\title{
Cathodic delamination at the polymer-to-metal interface of sea cable connector assemblies
}

\author{
Zakari Makama ${ }^{1,2,3}$, Ian Doble ${ }^{3,4}$, David Nicolson ${ }^{3}$, Mike E. Webb ${ }^{3}$ and James R. Smith ${ }^{1, *}$ \\ ${ }^{1}$ School of Pharmacy and Biomedical Sciences, University of Portsmouth, St Michael's Building, White Swan Road, \\ Portsmouth PO1 2DT, UK. \\ ${ }^{2}$ Now at: Department of Microbiology and Plant Botany, University of Oklahoma, Biocorrosion Centre, 770, Van \\ Fleet Oval, Norman, OK, 73019, USA. \\ ${ }^{3}$ Teledyne Impulse-PDM Ltd., 4-6 Alton Business Centre, Omega Park, Alton, Hampshire GU34 2YU, UK. \\ ${ }^{4}$ Now at: A-2-Sea Solutions Ltd., Unit 15, Romsey Industrial Estate, Greatbridge Road, Romsey, Hampshire SO51 \\ $O H R, U K$. \\ * Corresponding author \\ Email address: james.smith@ port.ac.uk (J.R. Smith).
}

Keywords: Polymer Coatings; Polyurethane; Stainless steel; Bronze; Titanium; Cathodic delamination; Corrosion; Cable connectors.

\begin{abstract}
Electrical and fibre optic cable connector assemblies are often required to operate under the very harsh environmental conditions experienced in the offshore oil and gas industry and on ships, autonomous underwater vehicles and remotely operated systems. These assemblies are frequently the source of failure and so must be sealed, mostly at the metal connector-to-cable interface. This is normally achieved using a polyurethane (PU) encapsulant system that bonds at the interface between the metal connector back-shell and the cable. In environments where sacrificial anodes are used, however, cable connector assemblies are prone to cathodic delamination $(\mathrm{CD}$, oxygen reduction increasing $\mathrm{OH}^{-}$concentration at the $\mathrm{PU} /$ metal interface), which can compromise PU-to-metal bonds causing failure. Materials that are resistant to $\mathrm{CD}$ failure are therefore highly desirable. New EC REACH legislation has further regulated the use of hazardous chemicals in the production and use of polymers. New, compliant materials have emerged, although lack well-established performance testing. Hence, in this work, stainless steel 316L, bronze CW451K, titanium Ti6Al4V, PU and commercially available primers (PR24 and PR91) were used to investigate $\mathrm{CD}$ failures in cable connector assemblies and galvanic coupling effects. Data obtained from long-term sea raft exposure trials and flowing natural seawater tank tests were used, for the first time, to validate short-term accelerated laboratory salt-spray testing of these materials. The failure rate due to $\mathrm{CD}$ was observed to decrease in the order: electrochemical potential > polymeric system > metal substrate, strongly suggesting that electrochemical potential has the most dominant effect on $\mathrm{CD}$ failure rates.
\end{abstract}

\section{Introduction}

Corrosion failures caused by cathodic delamination (CD) account for a significant portion of the annual corrosion costs to the oil and gas sector [1-2]. Such failures may lead to electrical shorting of cable connector assemblies and other corrosion failures, such as pitting, underfilm and hydrogen induced corrosion. These could cause sudden and catastrophic failures resulting in oil spills, if occurring in hydrocarbon carrying pipelines/vessels, and marine hardware failures [3-5].

This paper addresses CD of an encapsulating polymer (polyurethane, PU) used to adjoin cables (power transmission, fibre optics and telecommunications signals) to metal connector back-shells (mainly stainless steel) for use in harsh marine environments. These cables connector assemblies (Fig. 1) have also been used on remotely operated vehicles (ROVs) and underwater surveillance systems [6]. The design and surface pretreatment (prior to sealing with PU) of the connector back-shells has been discussed in detail elsewhere [7].

CD failures, which could lead to water ingress and loss of electrical resistance/short circuiting in cable connectors $[3,6]$, are thought to originate around a coating defect or bare metal regions present on the surface of a coated metal that is cathodically polarised whilst immersed in an electrolyte [8-16]. In marine cable connector assemblies, CD failures are usually characterised by three or more distinct failure modes: (i) failure at the metal/primer interface, (ii) 
failure at the primer/PU interface and (iii) failure at both of these interfaces (mixed mode failure) $[3,10]$. Failure within the bulk of the primer (cohesive failures) is also very likely [10]. CD is prevalent in systems or structures used in marine environments particularly where corrosion protection of metal by protective coatings and either sacrificial or impressed current cathodic protection methods are used [1,3-6]. In locations where sacrificial anodes are employed, CD resulting from a localised cathodic reaction is thought to be the reason for polymer-to-metal bond failure [1,3-6]. Cable connector assemblies coupled to dissimilar metals, other than sacrificial anodes, will also undergo galvanic corrosion or CD depending on the nobility of individual metals in the galvanic couple [4].

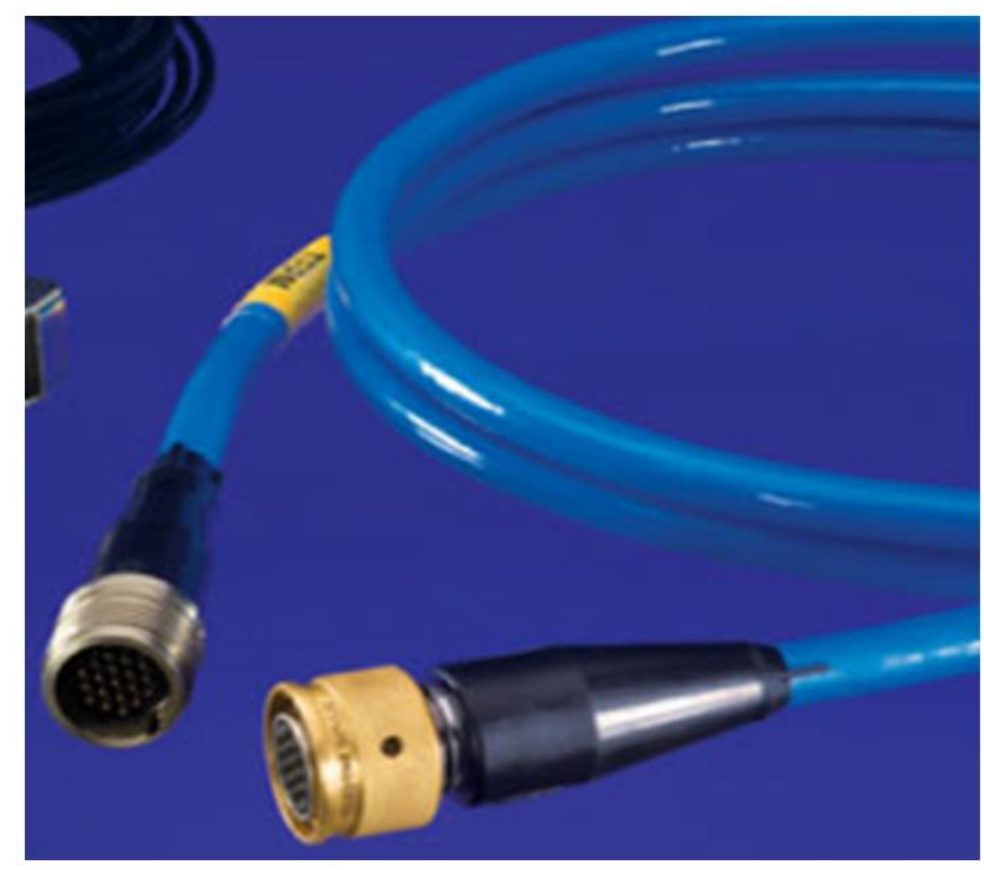

Fig. 1. A typical moulded cable connector assembly.

It is widely accepted that $\mathrm{CD}$ is caused by electrochemical reactions taking place at the metal substrate/polymer interface [4,8-15] and is influenced by a number of factors, including type of metal substrate, composition of electrolyte, electrochemical potential, coating characteristics and oxygen levels [4,6,8,13-14,17]. The numerous parameters involved have made mechanistic details difficult to evaluate $[1,17,18]$. Alkali conditions, generated due to electrochemical reactions taking place on cathodically polarised metal surfaces, are thought to be responsible for the loss of metal-to-polymer adhesion. Studies by Leng et al. characterised the mechanism of delamination of model coatings from a steel surface starting from a well-defined coating defect in the metal/polymer composite $[14,15]$. The delamination process is thought to be associated with a drop in electrode potential from very positive (anodic) values at an intact metal/polymer interface to negative values, which are typical of uncoated steel surfaces [14].

For the manufacture and sealing of cable connectors, the ability to select metal and polymer materials that can resist deterioration due to $\mathrm{CD}$ and degradation by other mechanisms is of critical importance. Following recent European Commission (EC) legislation requiring registration, evaluation, authorisation and restriction of chemicals (REACH) that further restricts the use of certain hazardous chemicals in the production and use of polymers, a surge in production of new, compliant materials has pursued $[19,20]$. Materials and design engineers are now saddled with the task of ensuring that new polymeric materials do not compromise performance or safety. Thus, polymer engineers and end users are faced with unresolved fundamental and practical issues regarding, for example, the type of test data, test methods, measurements and standard procedures required for robust assessment of the performance and safety of the new materials [20]. 
Until 3 - 4 decades ago, the formulations for most polymers were relatively stable, having well-established performance histories. New materials were evaluated simply by comparing the field performance of an established material with that of a new one [20]. Recent rapid changes in polymer formulations, chemistries and technologies have made this method impracticable because, unlike older, existing materials, new polymeric and composite materials do not have well-established performance histories that can be used for making durability comparisons and service life predictions $[10,20]$. The latter parameter based on long-term material performance histories have now become increasingly unpopular and unfeasible due to the long exposure periods required to acquire such data. Existing alternatives, i.e., short-term laboratory tests, are often unreliable and viewed with suspicion. For these reasons, requirement for a reliable service life prediction methodology for polymeric materials has remained a continuing need $[19,20]$. Data required for performance and service life-time predictions of new polymeric materials can be sourced from three major areas: fundamental mechanistic studies; laboratory accelerated ageing studies; and outdoor exposure studies [19]. The latter tests are almost always viewed as a de facto standard performance test against which other approaches must be compared, to establish their viability [21]. However, although outdoor exposure tests have played an important role in assessing the performance of polymers and are viewed as the "real-time test", it is argued that these tests, which are carried out under natural weather conditions, are neither repeatable nor reproducible and hence must be used with caution. In particular, the variability of weather conditions over the testing periods, often several years, has been of great concern [21]. The relationship between laboratory accelerated and outdoor exposure tests has remained an area of much research interest [22,23]. Deflorian et al. compared degradation rates for samples exposed in a salt-spray chamber with those for identical samples exposed in the natural outdoor environment and reported a positive correlation [23]. Their work was focused, however, on thinly coated $(5-100 \mu \mathrm{m})$ samples and to our knowledge, no research data exists where field exposure studies have been compared with accelerated laboratory tests for metal/PU composites used in marine cable connector assemblies. The majority of the published work have either focused on the kinetics of CD or the screening of commercially available polymers using accelerated laboratory methods. While these papers are interesting and may contribute to the understanding of $\mathrm{CD}$, they do not give a robust insight into the applicability of their findings in real-life applications.

With regard to the metal/PU interface in marine cable connector assemblies, the specific aims in this work were to: (i) understand the dominant and/or fundamental processes involved in CD failures; (ii) correlate failures from accelerated (salt-spray cabinet) tests with those from "real-life" flowing seawater tanks and on an exposure raft (Langstone Harbour, Portsmouth, UK); (iii) simulate the galvanic coupling effect of connecting cable assemblies to dissimilar metal appurtenances and contrast this with the absence of this effect on CD; and (iv) suggest the most appropriate service life conditions and design for maximising cable connector life-time expectancy.

\section{Experimental}

Three parallel exposure trial studies were initiated using nominally identical test frames. Two of these trials were outdoor, long-term trials consisting of test samples exposed in a tank (containing flowing natural seawater from Langstone Harbour, Portsmouth, UK) and on a sea raft (Langstone Harbour, UK). The outdoor exposures were carried out for 2 years at average Langstone Harbour seawater temperatures of $8{ }^{\circ} \mathrm{C}$ and $17{ }^{\circ} \mathrm{C}$ for the Winter and Summer periods, respectively. The third study was a laboratory accelerated test carried out using a salt-spray cabinet. The first two tests were designed to simulate failures in cable connector assemblies as experienced in the actual service condition using modelled samples whilst the salt-spray test accelerated such failures whilst under elevated stress conditions. X-ray diffraction (XRD) techniques were used to analyse corrosion products recovered from the failed sample interfaces and to identify the crystalline phases present. This helped to deduce the dominant failure mechanism(s) of the test samples following exposure.

\subsection{Materials and equipment}

Stainless steel 316L, bronze CW451K and titanium Ti6Al4V alloys were obtained from Aaron Metal and Plastics Suppliers Ltd., Bristol, UK. Brown angular $\mathrm{Al}_{2} \mathrm{O}_{3}$ and black SiC-rich grits used for surface preparation were supplied by Vixen Surface Treatment Ltd., Stockton-on-Tees, UK and Guyson International Ltd., North Yorkshire, $\mathrm{UK}$, respectively. The alloying elements $(\%)$ for stainless steel $316 \mathrm{~L}$, and the bronze and titanium alloys, respectively, were: Cr 16.00-18.00, Ni 10.00-14.00, Mo 2.00-3.00, Mn 2.00, N 0.10, Si 0.75, P 0.045, C 0.03, S 0.030; $\mathrm{Sn} 4.5-5.5, \mathrm{P} 0.01-0.4, \mathrm{Fe} \geq 0.1, \mathrm{Ni} \leq 0.2, \mathrm{Zn} \leq 0.2, \mathrm{~Pb} \leq 0.02$, other 0.2 max, Cu balance; Al 5.5-6.76, V 3.5$4.5, \mathrm{Fe}<0.25, \mathrm{O}<0.2, \mathrm{C}<0.08, \mathrm{~N}<0.05, \mathrm{H}<0.0125$, Ti balance [24]. 
Two polymeric primer coatings were used in the current study: a wash primer, PR24 (Lords Corporation Ltd., Manchester, UK), and a PU primer (PR91; Dow Hyperlast, Derbyshire, UK). The former consists of: an alcoholic dispersion of zinc tetraoxychromate $\left(\mathrm{ZrCrO}_{4} \cdot 4 \mathrm{Zn}(\mathrm{OH})_{2}\right)$ in poly(vinylbutyral) (PVB) (Part A, resin) and a dilute alcoholic solution of phosphoric acid (Part B, curing agent) (Table 1) [25,26], the product of which adheres well to a variety of metal and polymer surfaces; the chromates act to passivate the metal surfaces [26]. The most likely bond forming components of PR24 are PVB, phenol and phenolic resins; PVB is produced from the reaction of polyvinyl alcohol (PVA) and butyraldehyde (Fig. 2). PR91 was a two-part PU comprising a polyol (Part A) and an isocyanate (Part B), although the exact chemical composition was not made available. The use of PUs for pipeline coatings and various marine applications are well-reported [27-29]. Castable PU was also supplied by Dow.

Table 1. Chemical components of PR24 Parts A and B.

\begin{tabular}{|c|c|c|}
\hline Part & Name & $\begin{array}{l}\text { Concentration / } \\
\mathrm{w} / \mathrm{w} \%\end{array}$ \\
\hline A & $\begin{array}{l}\text { Acetic acid, 2-methoxy-1-methylethyl ester, (propylene glycol methyl ether } \\
\text { acetate) } \mathrm{CH}_{3} \mathrm{OCH}_{2} \mathrm{CH}\left(\mathrm{CH}_{3}\right) \mathrm{OCOCH}_{3}\end{array}$ & 30 \\
\hline A & Ethanol & 15 \\
\hline A & 2-Butanol & 15 \\
\hline A & Chromic acid (zinc chromate) $\mathrm{ZnCr}_{2} \mathrm{O}_{7}$ & 10 \\
\hline A & Poly(2-propyl- $m$-dioxane-4,6-diylene), (PVB resin) & 10 \\
\hline A & Phenolic resin & 9 \\
\hline A & $\begin{array}{l}\text { Dipropylene glycol methyl ether acetate } \\
\mathrm{CH}_{3} \mathrm{OCH}_{2} \mathrm{CH}\left(\mathrm{CH}_{3}\right) \mathrm{OCH}_{2} \mathrm{CH}\left(\mathrm{CH}_{3}\right) \mathrm{OCOCH}_{3}\end{array}$ & 5 \\
\hline A & Iron (III) oxide (red oxide pigment) & 4 \\
\hline A & Phenol & 1 \\
\hline A & Methanol & 1 \\
\hline B & 2-Butanol & 37 \\
\hline B & Ethanol & 33 \\
\hline B & $\begin{array}{l}\text { Acetic acid, 2-methoxy-1-methylethyl ester, (propylene glycol methyl ether } \\
\text { acetate) }\end{array}$ & $<20$ \\
\hline B & Dipropylene glycol, methyl ether $\mathrm{CH}_{3} \mathrm{OCH}_{2} \mathrm{CH}\left(\mathrm{CH}_{3}\right) \mathrm{OCH}_{2} \mathrm{CH}\left(\mathrm{CH}_{3}\right) \mathrm{OH}$ & $<4$ \\
\hline B & Phosphoric acid & $<2$ \\
\hline B & Methanol & $<2$ \\
\hline
\end{tabular}<smiles>CCCC(=O)OC(CC(O)CC(C)(C)C)CC1CC(C(C)(C)C)OC(CCC)O1</smiles>

Fig. 2. Formation of PVB from PVA and butyraldehyde.

The grit-blasting equipment employed was a Vixen Jet air VM42 blast cabinet (Vixen, Stockton on Tees, UK) [7]. Surface preparation of metal substrates, priming and test sample moulding using injection moulding (Unipre G31, Unipre GmbH, Werl, Germany) were carried out according to standard procedures (PDM/STD/3009: TeledyneImpulse PDM, Alton UK) [30]. XRD analysis of corrosion products was carried out using an XRD PW1729 X-ray generator $2 \theta$ (Philips, Cambridge, UK). The salt-spray equipment used for neutral salt-spray testing was the 
Gallenkamp Industrial SSC1000/E (Weiss Gallenkamp Ltd, Loughborough, UK). Test samples were tested according salt-spray specification ASTM B117 [31], using a fog mist from $\mathrm{NaCl}$ solution $(3.5 \mathrm{w} / \mathrm{v} \%)$ to mimic artificial seawater salinity of $3.5 \mathrm{w} / \mathrm{v} \%$. A continuous spray cycle testing was employed at $35{ }^{\circ} \mathrm{C}$ and $95-98 \%$ relative humidity for a period of about 4 months. The equipment was only switched off for short intermittent durations to replenish the $\mathrm{NaCl}$ solution reservoir, humidity moisture tank and to examine the test samples for signs of delamination failure. Sample assessment for delamination failure (metal-to-polymer bond strength testing) was carried out using a Super Samson spring balance $(20 \mathrm{~kg}$, Salter Brecknell, Melbourne Australia).

\subsection{Test sample preparation}

The metal substrates ( $3 \mathrm{~mm}$ thickness) were received with a machined (ground) surface finish. They were cut into test pieces $(100 \mathrm{~mm} \times 25 \mathrm{~mm})$, and a $6 \mathrm{~mm}$ diameter hole was drilled into one end of each of the test pieces for sample attachment. They were then grit-blasted $\left(\mathrm{Al}_{2} \mathrm{O}_{3}\right.$ or $\mathrm{SiC}$ grit) [7], primed (either PR24 or PR91), allowed to dry and then over-moulded with castable PU in permanent open-fill PU moulds (Fig. 3). Prior to moulding, $c a .10$ $\mathrm{mm}$ of the drilled end of the coated metal test pieces were masked with adhesive tape to create an unbounded free end for sample attachment onto testing rigs and for bond or adhesion testing following exposure.

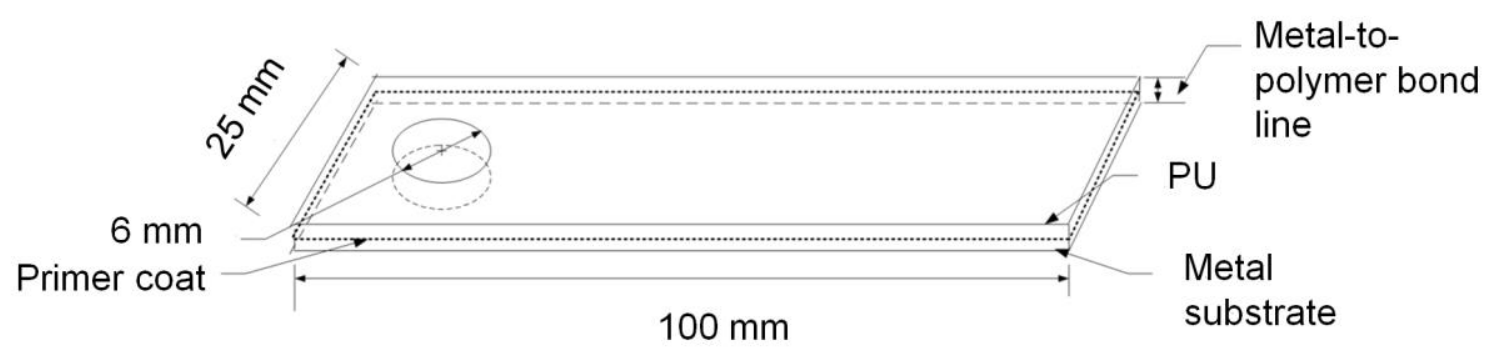

(a)

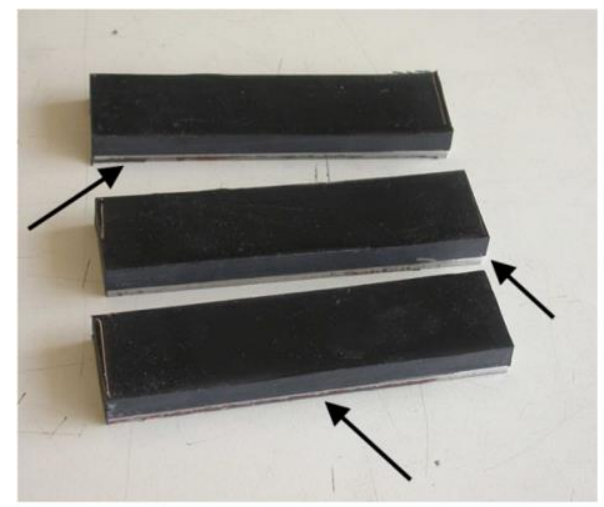

(b)

Fig. 3. (a) Schematic of a test sample comprising of metal/primer/PU composite. (b) Photographs of moulded metal/primer/PU composite test samples showing revealed bond-line (black arrows).

\subsection{Test rig design}

The test rig was designed to allow the moulded test samples to be subjected to electrical stresses by attaching them to a carbon steel metal frame $(686 \times 600 \mathrm{~mm})$ such that the samples were either directly electrically connected to or isolated from the frame, using steel nuts/bolts with isolation sleeves/washers as appropriate (Fig. 4). The carbon 
steel frame was cathodically protected using $\mathrm{Zn}$ anodes, hence simulating actual service environments thought to be favourable to $\mathrm{CD}$ failures in cable connector assemblies $[1,3,6]$. These two sample attachment configurations were introduced into the test rig design to simulate the galvanic coupling effect of connecting dissimilar metals to test samples and to contrast this with the absence of this effect. They also served to establish whether this had an effect on the rate of $\mathrm{CD}$ failure in cable connector assemblies. Electrical conducting wires were attached to selected test samples using crimp-on terminals that were connected to the samples. The other ends of the wires were terminated using banana-plugs that were used to connect a digital voltmeter (to measure electrochemical potential differences). The carbon steel beam (with attached test samples) was attached to the carbon steel frame, cathodically protected with zinc anodes $\left(68 \mathrm{~cm}^{3}\right)$. Three identical frames were manufactured and these assemblies were separately exposed in a salt-spray cabinet, seawater tank and on a sea-exposure raft.

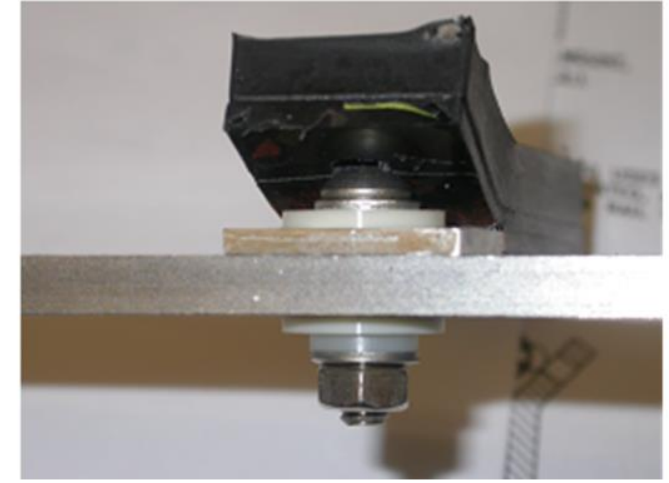

(a)

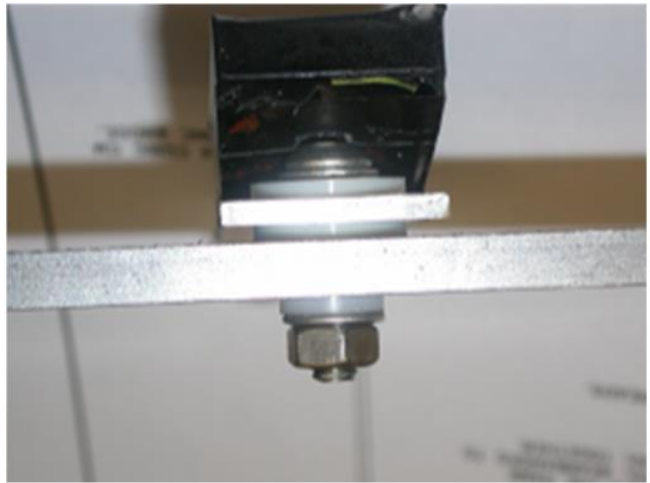

(b)

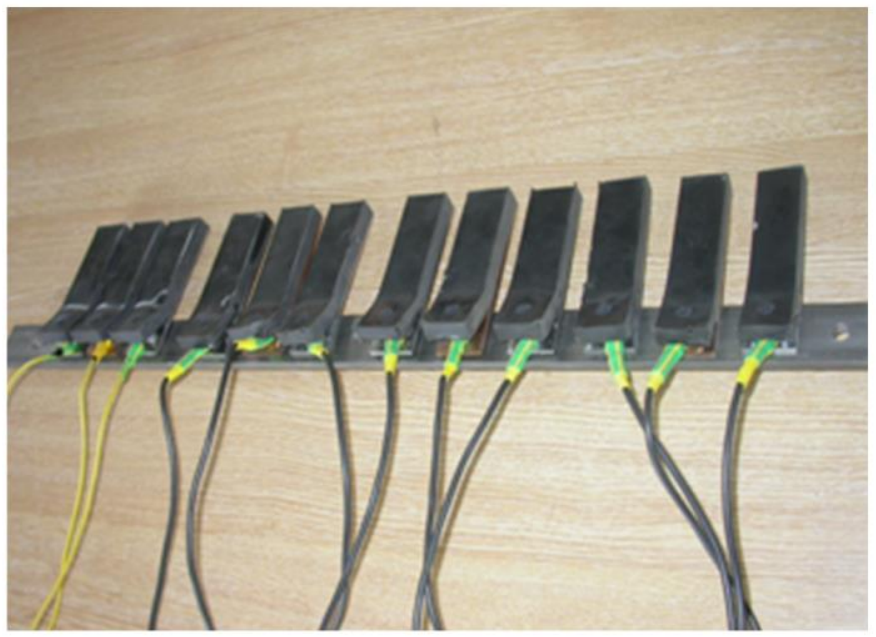

(c)

Fig. 4. Photographs showing (a) connected and (b) isolated test sample configurations, (c) photograph of samples attached to a carbon steel beam together with crimp-on conducting wires for measuring rest potentials in seawater.

\subsection{Bond testing and delamination kinetics}

The metal/polymer interface of each horizontally-held test sample (metal-to-polymer bonded area $c a .2000 \mathrm{~mm}^{2}$ prior to exposure) could withstand (without separation) a load of $c a . \geq 80 \mathrm{~N}$ applied vertically from one end using a hand-held spring balance (Salter Brecknell Smethwick, West Midlands, UK). Unexposed test samples having met this criterion were considered to possess $100 \%$ bond resistance and failure was measured as a percentage reduction 
in the original bonded area as a function of time measured from the forward-facing end of the delamination front of the test sample (when PU just began to peel from the metal; Fig. 5a).

(a)
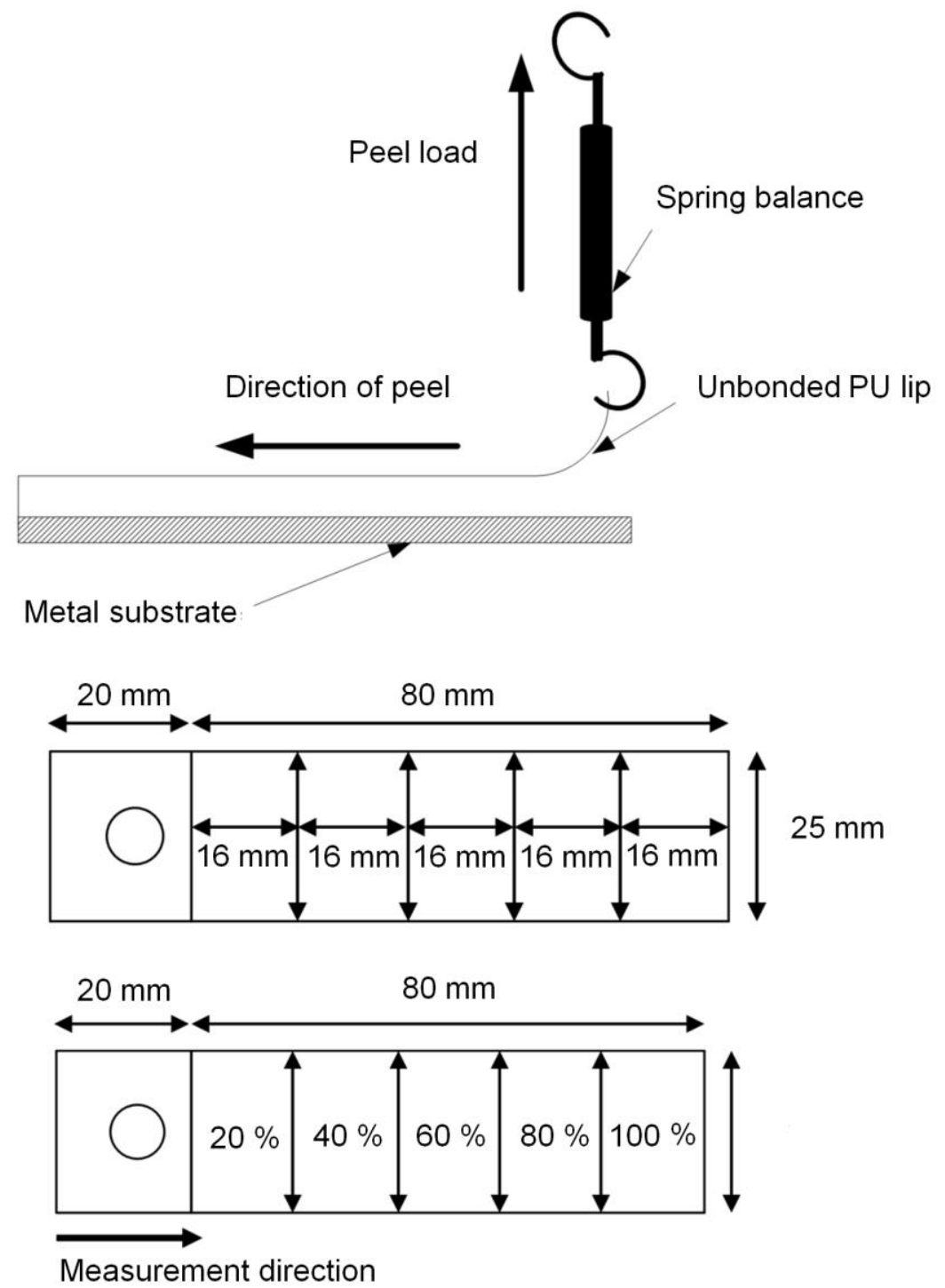

(b)

Fig. 5. Schematics of (a) bond testing of exposed samples using a spring balance, and (b) the test sample bond area and relative percentage failure measurement criterion.

The relative percentage reduction in bonded area due to delamination was measured using the standard surface area of the test samples (Eq. 1; Fig. 5b),

$B F=100\left(A_{0}-A_{f}\right) / A_{0}$

where $B F=\%$ bond failure, $A_{0}=$ initial bonded area, and $A_{f}=$ final bonded area

The $B F$ values were converted to equivalent surface area $\left(\mathrm{mm}^{2}\right)$ and plotted against 
(time / h $)^{0.5}$. The slopes of these plots were used to determine the kinetics of cathodic delamination of exposed test samples according to Arrhenius rate law (Eq. 2 and 3) [3,32],

$R=A e^{-E_{a} / k T}$

where $R=$ reaction rate, $A=$ constant, $E_{a}=$ activation energy, $k=$ Boltzman constant $\left(8.6171 \times 10^{-5} \mathrm{eV}\right), T=$ temperature $(\mathrm{K})$.

Taking natural logs of Eq. 2, $E_{a}$ may be obtained (Eq. 3): [27]

$\ln R=-\left(\frac{E_{a}}{k T}\right)+\ln A$

Assuming constant temperature, the CD rate $(R)$ is equivalent to the slope of the linear plots of (delaminated area / $\left.\mathrm{mm}^{2}\right)^{0.5}$ vs. (time / h) $)^{0.5}$. The slopes were squared and substituted into Eq. 3 to obtain CD rates in $\mathrm{mm}^{2} \mathrm{~h}^{-1}$. The adequacy of Eq. 3 has been confirmed experimentally and may be used to describe failures due to diffusion in solid state devices and other metal and polymer composites. In relevant products and failure modes, the test data fits the Arrhenius equation and yields straight line plots. When the relationship holds, this suggests a mechanism of failure by degradation due to a single chemical reaction or by diffusion [3,32]. Products tested using this model are assumed to fail when the single chemical reaction has produced a critical amount of reaction products or when the product has diffused $[3,32]$.

\subsection{Potential measurements}

The electrochemical potentials of the test samples in seawater were measured against $\mathrm{Ag} / \mathrm{AgCl}$ reference electrode. Measurements were obtained using a high-impedance digital multimeter (Tenma 72-7930, OH, USA). The impedance of the reference electrode was $<1 \mathrm{k} \Omega$ throughout the measurements.

\section{Results and discussion}

\subsection{Characteristic interfacial failure patterns and cathodic delamination rates}

Following exposure, the observed failure patterns varied with sample attachment configuration. For samples tested using "connected" test configuration, i.e., by electrically connecting the test samples to a carbon steel beam, this consisted of a central rectangular island of primer, still attached to the metal (Zone 2; Fig. 6). This island of primer was surrounded by an area of relatively clean metal regions along the edges of the metal plate (Zone 1, Fig. 6a). The failed PU interface of the test sample was an exact mirror image of the failed metal interface. For the "isolated" test samples, i.e., samples electrically isolated from the carbon steel beam, visual and microscopic examination revealed a thin primer layer on both metal and PU failure interfaces (Fig. 6b) suggesting that failure had occurred in the bulk of the primer. The failure modes observed in these test samples were similar in characteristic to those reported by Watts et al. [10-11]. Using XPS, they observed that cathodically polarised coated steel panels failed through a two stage process characterised by two regions that consisted of a clean, matt-grey steel substrate adjacent to adhering polymer [10]. In test panels tested under a free corrosion potential, referred to as isolated samples in this work, Watts et al. observed that the failure, though close to the surface, occurred within the bulk of the primer [10,11]. They concluded that these failure regions (Zone 1 and Zone 2) were the result of different levels of alkalinity caused by different diffusion paths of $\mathrm{Na}^{+}$, i.e., lateral and downward diffusion of cations, respectively [10]. Although down-diffusion, as described by Watts et al. and initially proposed by Kendig et al. [33], might be true for a thin high-permeable polymer film, this argument was thought be highly unlikely in the systems considered in this work due to the thickness $(\sim 10 \mathrm{~mm})$ and very low water absorption $(2.1 \% ; 1000 \mathrm{~h}$ at NTP) characteristic of the PU encapsulate (EMC 80A) used [34]. Lateral diffusion through the edges was believed to be the only likely pathway for ions to the PU/metal interface. These results are also consistent with the recent finding of Ramotowski et. al. [3] and gave confidence to conclude that the patchy rectangular primer region (Zone 2) on the failed metal surface was caused by weakening of the primer/PU interface due to lateral diffusion of ions through the edges of the sample. CD is believed to have been initiated at the edges of the sample and propagated (inwards) through the clean metal region (Zone 1) due to the accumulation of $\mathrm{OH}^{-}$from the oxygen reduction reaction (Eq. 4),

$\mathrm{O}_{2}(\mathrm{~g})+2 \mathrm{H}_{2} \mathrm{O}(\mathrm{l})+4 \mathrm{e}^{-} \rightarrow 4 \mathrm{OH}^{-}(\mathrm{aq})$

(Eq. 4) 
and/or seawater ingress through the edges of the samples. The surface areas of these two regions, i.e., Zones 1 and 2, were observed to vary with exposure time. Whilst the area of the former increased, that of the latter was observed to decrease, with exposure time. This was also consistent with the findings of Ramotowski et al. [3]. On the application of a pull force during intermittent bond tests, the locus of failure transits from the metal/primer interface (Zone 1) to the primer/PU interface (Zone 2) due to the already weakened primer layer. Hence, a rectangular primer patch is still left attached to the metal, which is characteristic of CD surfaces (Fig. 7). Since the surface area of Zone $1\left(A_{1}\right)$ was inversely proportional to that of Zone $2\left(A_{2}\right)$ as a function of time, $A_{1}$ was used as a variable to calculate the cathodic delamination kinetics $[3,27]$. In seawater immersion tests, the rates of cathodic delamination were determined by calculating the slopes of the plots of $\left(A_{l} / \mathrm{mm}^{2}\right)^{0.5}$ vs. (time / h $)^{0.5}$. For stainless steel samples prepared using PR24, samples tested using connected test configuration failed in $<2$ months of exposure, i.e., before the first $\% \mathrm{BF}$ data was collected. The corresponding bronze CW451K and titanium Ti6Al4V test samples failed within a period of $\sim 4$ months at CD rate of $c a .3 \mathrm{~mm}^{2} \mathrm{~h}^{-1}$ (Table 2).
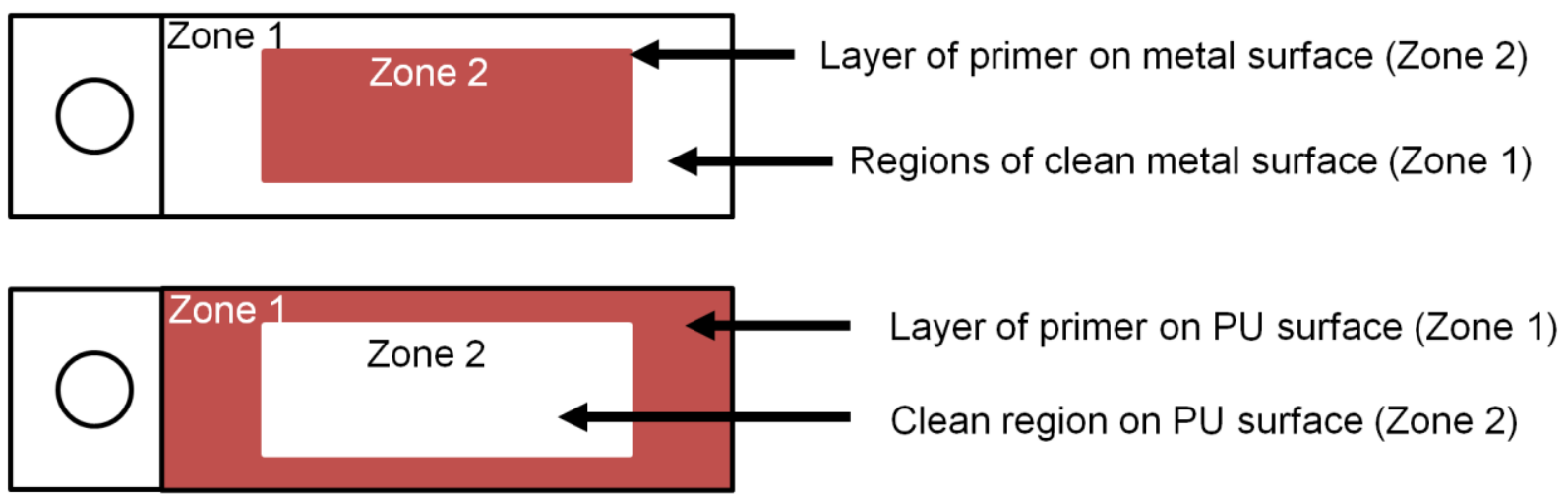

(a)

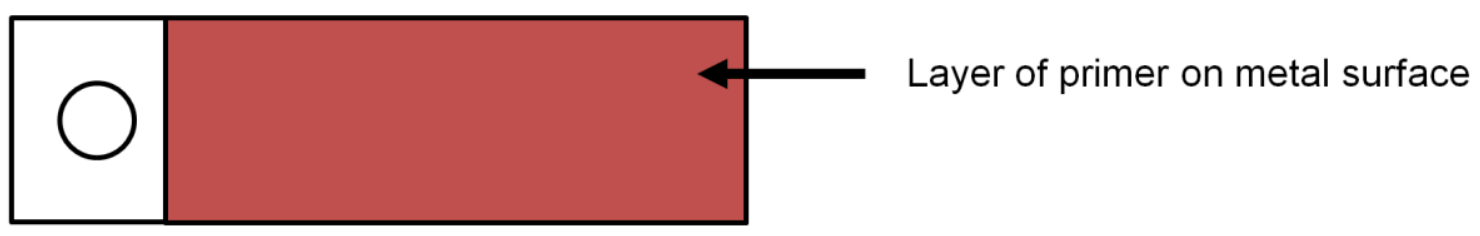

Metal substrate

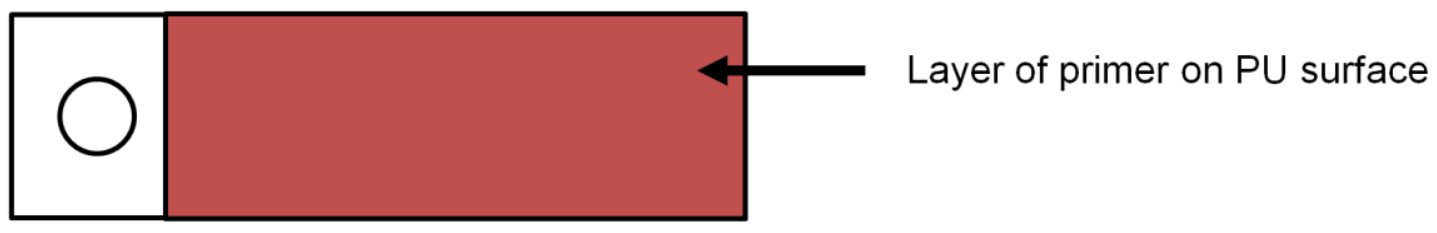

PU substrate

(b)

Fig. 6. Schematics of the failure patterns of (a) connected samples showing metal interface with a rectangular patch of primer (Zone 2) surrounded by regions of relatively clean metal edges (Zone 1); note the PU interface is an exact mirror image of the metal substrate; $(b)$ isolated test samples showing metal and PU interface covered with a thin layer of primer. 


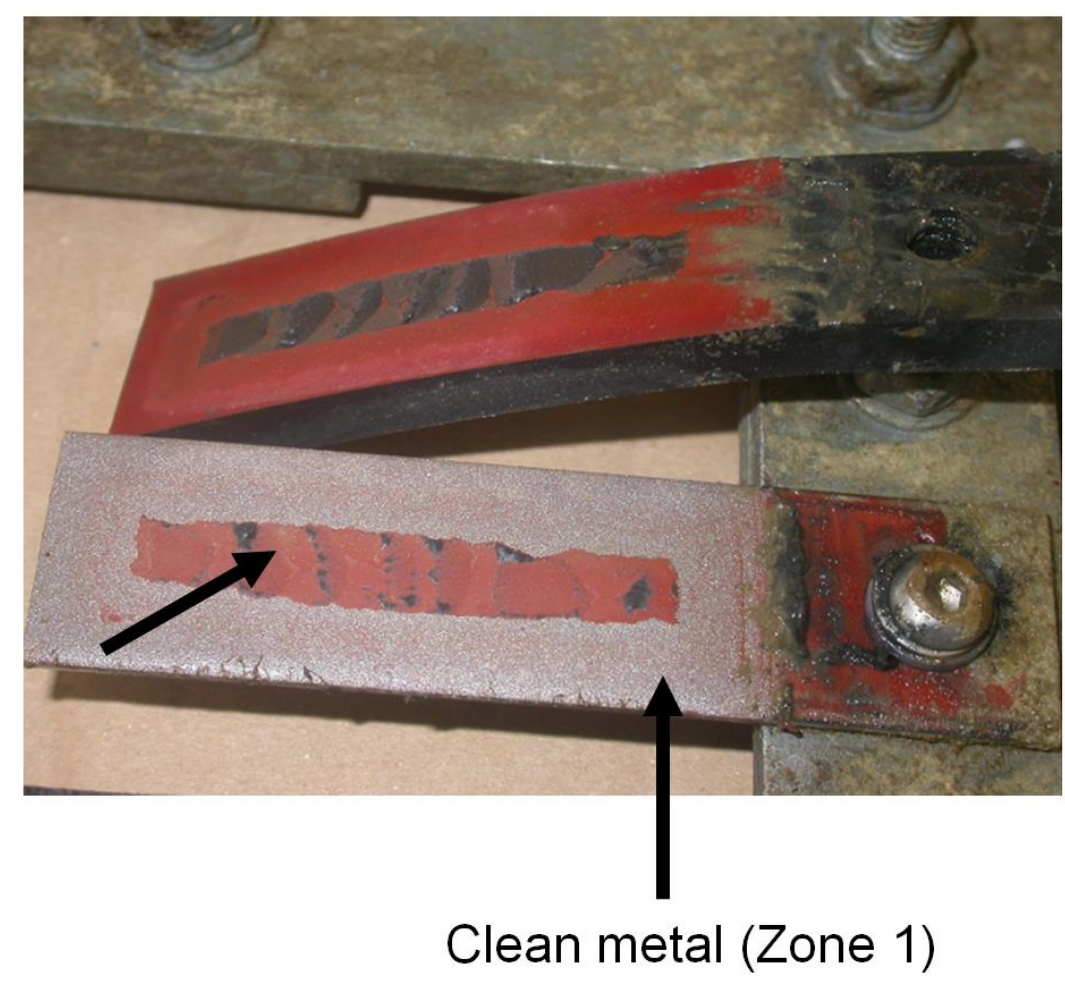

Fig. 7. Photographs of failed test samples showing zones 1 and 2 failure patterns of samples primed with PR24 and having direct electrical connection to the carbon steel beam.

Table 2. Summary of experimentally calculated cathodic delamination rates in seawater exposure trial*.

\begin{tabular}{|c|c|c|c|c|c|c|c|}
\hline & $\begin{array}{l}\text { Sample 1 } \\
\text { slope / } \\
\left(\mathrm{mm}^{2} \mathrm{~h}^{-1}\right)^{0.5}\end{array}$ & $\begin{array}{l}\text { Sample 2 } \\
\text { slope / } \\
\left(\mathrm{mm}^{2} \mathrm{~h}^{-1}\right)^{0.5}\end{array}$ & $\begin{array}{l}\text { Mean slope / } \\
\left(\mathrm{mm}^{2} \mathrm{~h}^{-1}\right)^{0.5}\end{array}$ & $\begin{array}{l}\text { Slope }{ }^{2 /} \\
\mathrm{mm}^{2} \mathrm{~h}^{-1}\end{array}$ & $\begin{array}{l}\text { Delamination } \\
\text { rate, } \ln \text { (slope / } \\
\mathrm{mm}^{2} \mathrm{~h}^{-1} \text { ) }\end{array}$ & $\begin{array}{l}\text { X-axis } \\
\text { intercept, } \\
(t / h)^{0.5}\end{array}$ & $\begin{array}{l}\text { Delay } \\
\text { time } \\
/ \mathrm{h}\end{array}$ \\
\hline \multicolumn{8}{|c|}{ PR 24 connected } \\
\hline $\mathrm{S}$ & - & - & - & - & - & - & - \\
\hline B & 4.032 & 3.852 & 3.942 & 15.536 & 2.743 & 41.0 & 1681 \\
\hline $\mathrm{T}$ & 4.215 & 4.008 & 4.111 & 16.904 & 2.828 & 41.3 & 1701 \\
\hline \multicolumn{8}{|c|}{ PR24 isolated } \\
\hline $\bar{S}$ & 2.217 & 1.720 & 1.969 & 3.875 & 1.355 & 40.0 & 1600 \\
\hline B & 2.217 & 2.726 & 2.471 & 6.108 & 1.810 & 43.5 & 1892 \\
\hline $\mathrm{T}$ & 3.785 & 2.941 & 3.363 & 11.309 & 2.426 & 44.5 & 1980 \\
\hline \multicolumn{8}{|c|}{ PR91 connected } \\
\hline $\mathrm{S}$ & 1.714 & 1.595 & 1.654 & 2.736 & 1.007 & 40.5 & 1640 \\
\hline B & 1.396 & 1.270 & 1.332 & 1.775 & 0.574 & 35.0 & 1225 \\
\hline $\mathrm{T}$ & 1.603 & 1.459 & 1.531 & 2.344 & 0.852 & 46.5 & 2162 \\
\hline
\end{tabular}

* $\mathrm{S}=$ Stainless steel 316L, B = bronze CW451K, T = Titanium Ti6Al4V. 
Similarly, stainless steel samples prepared using PR24 but tested using the isolated test configuration were observed to have a slower delamination rate $\left(1.35 \mathrm{~mm}^{2} \mathrm{~h}^{-1}\right)$. The corresponding bronze CW451K and titanium Ti6Al4V had identical delamination rates of $c a .2 \mathrm{~mm}^{2} \mathrm{~h}^{-1}$. Generally, the isolated samples showed higher delamination resistance (ca. $25-100 \%$ ) compared to nominally identical samples tested using connected test sample configurations (Tables 2 and 3$)$.

In samples prepared using PR91 and tested using connected test configuration, stainless steel 316L had CD rates of ca. $1 \mathrm{~mm}^{2} \mathrm{~h}^{-1}$ while bronze CW451K and titanium Ti6Al4V showed delamination rates of 0.85 and $0.51 \mathrm{~mm}^{2} \mathrm{~h}^{-1}$, respectively. The Arrhenius relationship did not hold for nominally identical samples prepared with PR91 and tested using isolated test configuration. In the latter case, no failure was observed for $>1$ year of exposure period in the seawater environment.

It was also observed that the straight lines plots had slopes with $R^{2}$ values $>0.9$ indicating a strong relationship between $A_{1}$ and time. The lines did not intercept the x-axis at zero, indicating the presence of an incubation period prior to the initiation of CD failure in the test samples. The average delay time or incubation period was $c a .1400 \mathrm{~h}$ prior to the onset of CD failure. The highest incubation period $(2162 \mathrm{~h})$ was observed for Ti6Al4V samples prepared with PR91 and tested using isolated test configuration (Table 2). This observation was consistent with that of Ramotowski et al. who observed that the magnitude of the incubation periods varied with temperature and type of polymeric composite material [3].

\subsection{Correlation of accelerated salt-spray tests with flowing seawater tanks and exposure raft}

Generally, higher failure rates were observed in tests carried out in the salt-spray cabinet compared to seawater exposure trials (Table 3 ). This was believed to be due to higher testing temperatures $\left(35^{\circ} \mathrm{C}\right)$ in the former compared to the later $\left(8\right.$ and $\left.17^{\circ} \mathrm{C}\right)$. The delay or incubation time prior to the onset of $\mathrm{CD}$ failure was also observed to be markedly lower in the salt-spray test compared to seawater exposure trials (Tables 2 and 4). Tests carried out in these environments were observed to show similar results in terms of overall primer resistance, failure mechanism(s) and failure patterns (Fig. 6). The data obtained indicated that the polymer-to-metal bond life-time expectancy of primer PR91 was at least twice that of PR24 in all test conditions (Table 3). The results showed that the former had better resistance to failure than the latter, e.g., when applied to stainless steel 316L and tested using "connected" test configuration in seawater trials, failure occurred within 3-4 months as compared to 5-6 months in samples treated with PR24 and PR91, respectively. Although test sample configurations appeared to have had no significant effect on tests carried out in the salt-spray cabinet, the CD rates were also observed to be higher in PR24 samples compared to PR91 (Tables 2 and 4). However, irrespective of the primer type used, samples tested using connected test configuration were generally observed to have a higher rate of $\mathrm{CD}$ failure than those tested using the isolated test configuration in seawater (Tables 2 and 3). The increased failure rate was thought to be due the added effect of galvanic coupling of the samples to the carbon steel beam on the test frame. Since the carbon steel beam corroded preferentially to the stainless steel $316 \mathrm{~L}$ in connected samples, the electrons generated by the anodic reaction (taking place on the carbon steel) were available for the cathodic oxygen reduction reaction (Eq. 4) which occurs on the stainless steel 316L surface (cathode). The $\mathrm{OH}^{-}$ions generated by this reaction, we suggest, enhanced $\mathrm{CD}$ failures in these samples. Also, in the isolated test configuration, it was observed that samples treated with PR91 and having their polymer-to-metal bond-lines unexposed during testing, i.e., with their edges totally encapsulated in PU, had the longest failure resistance (> 2 years) in seawater immersion trials. These results were consistent with those of Ramotowski et al. [3], who in similar experiments using monel 400 alloy as the metal substrate, found that CD propagated via exposed polymer/metal bond-lines [3]. This gave us the confidence to surmise that the absence of a "defect", i.e., exposed metal at the sample edges in this case, in which water and/or ions could laterally diffuse to the metal/polymer interface, could further enhance resistance to $C D$ and increase cable connector service life expectancy. The better failure resistance exhibited by PR91 was thought to be partly due to its generic properties being identical to and hence compatible with those of the overlaid PU [27,28]. Generic compatibility is key to the adhesion between two polymer materials and in the formation of more resistant bonds across the metal/primer/PU interface $[27,28]$. Thus, PR24 would be expected to be less compatible with PU and lead to greater failure. 
Table 3. Summary of time-to-failure of metal/polymers systems in exposure tests*.

\begin{tabular}{|c|c|c|c|c|c|c|c|}
\hline \multirow[t]{2}{*}{ Primer } & \multirow[t]{2}{*}{ Substrate } & \multicolumn{3}{|c|}{$\begin{array}{l}\text { Time-to-failure when connected to } \\
\text { carbon steel frame for different } \\
\text { immersion test types }\end{array}$} & \multicolumn{3}{|c|}{$\begin{array}{l}\text { Time-to-failure when isolated from carbon } \\
\text { steel frame for different immersion test } \\
\text { types }\end{array}$} \\
\hline & & SW & SR & SS & SW & SR & SS \\
\hline \multirow[t]{3}{*}{$\begin{array}{l}\text { PR24 } \\
\end{array}$} & $316 \mathrm{~L}$ & $3-4 m$ & $3-4 m$ & $23 \mathrm{~d}$ & $5-6 m$ & $5-6 m$ & $23 \mathrm{~d}$ \\
\hline & CW451K & $3-4 m$ & $3-4 m$ & $23 \mathrm{~d}$ & $5-6 m$ & $5-6 m$ & $23 \mathrm{~d}$ \\
\hline & Ti6Al4V & $3-4 m$ & $3-4 m$ & $23 \mathrm{~d}$ & $5-6 m$ & $5-6 m$ & $23 \mathrm{~d}$ \\
\hline \multirow[t]{3}{*}{ PR91 } & $316 \mathrm{~L}$ & $6 \mathrm{~m}$ & $5-6 m$ & $\mathrm{NF}(2 \mathrm{~m})$ & $\mathrm{NF}$ & $5-6 m$ & $\mathrm{NF}(2 \mathrm{~m})$ \\
\hline & CW451K & $6 \mathrm{~m}$ & $5-6 m$ & $\mathrm{NF}(4 \mathrm{~m})$ & NF & $\mathrm{NF}$ & $\mathrm{DF}(40 \%)$ \\
\hline & Ti6Al4V & $6 \mathrm{~m}$ & $5-6 m$ & $\mathrm{DF}(15 \%)$ & $\mathrm{NF}$ & $\mathrm{NF}$ & $\mathrm{DF}(40 \%)$ \\
\hline
\end{tabular}

* $\mathrm{SW}=$ seawater, $\mathrm{SR}=$ sea raft, $\mathrm{SS}=$ salt-spray; $\mathrm{m}=$ months, $\mathrm{d}=$ days; $\mathrm{NF}=$ no failure (after stated number of months); $\mathrm{DF}=$ decreased failure (by stated \%).

Table 4. Summary of experimentally calculated cathodic delamination rates in the salt-spray cabinet*.

\begin{tabular}{|c|c|c|c|c|c|}
\hline & $\begin{array}{l}\text { Sample 1 } \\
\text { slope / } \\
\left(\mathrm{mm}^{2} \mathrm{~h}^{-1}\right)^{0.5}\end{array}$ & $\begin{array}{l}\text { Sample 2 } \\
\text { slope / } \\
\left(\mathrm{mm}^{2} \mathrm{~h}^{-1}\right)^{0.5}\end{array}$ & $\begin{array}{l}\text { Delamination } \\
\text { rate, } \ln \text { (slope / } \\
\mathrm{mm}^{2} \mathrm{~h}^{-1} \text { ) }\end{array}$ & $\begin{array}{l}\text { X-axis } \\
\text { intercept, } \\
(t / h)^{0.5} \\
\end{array}$ & $\begin{array}{l}\text { Delay } \\
\text { time } \\
/ \mathrm{h}\end{array}$ \\
\hline \multicolumn{6}{|c|}{ PR24 connected } \\
\hline$S$ & 2.819 & 7.946 & 2.073 & 7.0 & 49 \\
\hline B & 2.819 & 7.946 & 2.073 & 7.0 & 49 \\
\hline $\mathrm{T}$ & 2.246 & 5.046 & 1.619 & 4.0 & 16 \\
\hline \multicolumn{6}{|c|}{ PR24 isolated } \\
\hline$S$ & 5.244 & 27.501 & 3.314 & 15.0 & 225 \\
\hline B & 4.240 & 17.973 & 2.889 & 12.0 & 144 \\
\hline $\mathrm{T}$ & 2.246 & 5.046 & 1.619 & 5.0 & 25 \\
\hline \multicolumn{6}{|c|}{ PR91 connected } \\
\hline$S$ & 3.535 & 12.498 & 2.526 & 40.0 & 1600 \\
\hline B & NFR & NFR & NFR & NFR & NFR \\
\hline $\mathrm{T}$ & 0.386 & 0.149 & -1.904 & 17.0 & 289 \\
\hline \multicolumn{6}{|c|}{ PR91 isolated } \\
\hline $\mathrm{S}$ & 1.180 & 1.391 & 0.330 & 27.0 & 729 \\
\hline B & 1.160 & 1.344 & 0.296 & 30.0 & 900 \\
\hline $\mathrm{T}$ & 0.754 & 0.569 & -0.564 & 17.0 & 289 \\
\hline
\end{tabular}

* $\mathrm{S}=$ Stainless steel 316L, B = bronze CW451K, T = Titanium Ti6Al4V; NFR = no failures recorded.

\subsection{Effect of galvanic coupling on test samples}

In terms of electrochemical potential differences due to galvanic coupling in flowing seawater, all samples tested using the connected test sample configuration, were found to possess electrochemical potentials that were at the onset of $c a .-560 \pm 2 \mathrm{mV} v s$. $\mathrm{Ag} / \mathrm{AgCl}$ (Table 5). These potentials shifted to more negative values of $-860 \pm 2 \mathrm{mV} v s$. $\mathrm{Ag} / \mathrm{AgCl}$ within a month and remained constant for 3 months (Table 5). These potential trends were the same irrespective of the metal substrate type or polymeric system used (Table 5). The electrochemical potentials were as a result of the galvanic coupling effect arising from electrically connecting the test samples to the carbon steel frame, the latter being anodic to the former will have altered its electrochemical potential in the negative direction and would corrode preferentially when electrically connected in seawater. This phenomenon was also suggested by 
Arnett et al. [4], who conducted research on non-conducting coatings on metal connector back-shells and found identical electrochemical potentials $(-800 \mathrm{mV} v s$. SCE) to be favourable to CD via the electrochemical reaction (Eq. 4) [4].

Table 5. Test sample potentials measured in flowing seawater tank*.

\begin{tabular}{|c|c|c|c|c|c|c|c|c|c|c|c|c|}
\hline \multirow{4}{*}{$\begin{array}{l}\text { Duration / } \\
\text { days }\end{array}$} & \multicolumn{12}{|c|}{$E v s . \mathrm{Ag} / \mathrm{AgCl} / \mathrm{mV}$} \\
\hline & \multicolumn{6}{|c|}{ PR24 } & \multicolumn{6}{|c|}{ PR91 } \\
\hline & \multicolumn{3}{|c|}{ Connected } & \multicolumn{3}{|c|}{ Isolated } & \multicolumn{3}{|c|}{ Connected } & \multicolumn{3}{|c|}{ Isolated } \\
\hline & $\mathrm{S}$ & $\mathrm{B}$ & $\mathrm{T}$ & $\mathrm{S}$ & $\mathrm{B}$ & $\mathrm{T}$ & $\mathrm{S}$ & $\mathrm{B}$ & $\mathrm{T}$ & $\mathrm{S}$ & $\mathrm{B}$ & $\mathrm{T}$ \\
\hline 1 & -559 & -560 & -561 & -195 & -227 & -195 & -560 & -560 & -561 & -280 & -230 & -206 \\
\hline 2 & -599 & -600 & -600 & -196 & -226 & -178 & -606 & -607 & -607 & -212 & -230 & -201 \\
\hline 3 & -701 & -701 & -701 & -118 & -220 & -170 & -700 & -699 & -698 & -141 & -218 & -169 \\
\hline 4 & -708 & -709 & -709 & -58 & -200 & -54 & -710 & -710 & -710 & -82 & -212 & -109 \\
\hline $5-14$ & -714 & -714 & -714 & -38 & -175 & -58 & -715 & -715 & -715 & -96 & -185 & -100 \\
\hline $15-30$ & -711 & -711 & -710 & +2.5 & -141 & -87 & -712 & -711 & -712 & -117 & -163 & -119 \\
\hline $30-60$ & -860 & -860 & -860 & +42 & -786 & +31 & -859 & -858 & -859 & -805 & -234 & -677 \\
\hline $60-90$ & -853 & -853 & -853 & -97 & -774 & +24 & -853 & -852 & -852 & -806 & -234 & -803 \\
\hline $90-365$ & - & - & - & -103 & - & - & - & - & -742 & -638 & -174 & -570 \\
\hline
\end{tabular}

* $\mathrm{S}=$ Stainless steel 316L, $\mathrm{B}=$ bronze CW451K, $\mathrm{T}$ = Titanium Ti6Al4V.

Samples tested using the isolated test sample configuration were found to have electrochemical potential in seawater that were initially negative values before shifting to more positive values during the first 30 days of measurement (Table 5). During this period, potentials fluctuated from -280 to $+42 \mathrm{mV} v s$. $\mathrm{Ag} / \mathrm{AgCl}$ on stainless steel $316 \mathrm{~L}$ samples, -230 to $-140 \mathrm{mV}$ on bronze and -206 to $-87 \mathrm{mV}$ when using Ti6Al4V test samples (Table 5). After 1 month of exposure, these potentials shifted to values more negative than $-500 \mathrm{mV} v s . \mathrm{Ag} / \mathrm{AgCl}$ in some of the test samples. This negative shift was found to be related to an accumulation of corrosion products between the underside of the test sample and the carbon steel beam, which caused an electrical connection between them. Although the predominant mode of failure in isolated test samples was characterised by a layer of primer on both failure interfaces (metal and PU; Fig. 6b), a visual examination of the failed metal interfaces of the test samples that experienced electrical shorting (due to underside accumulation of corrosion products), revealed the onset of a rectangular, patchy primer surrounded by regions of relatively clean metal surface that extended $c a .1 \mathrm{~mm}$ inward from the edges of the failed metal interface. The failed PU interface was an exact mirror image (Fig. 7). This was consistent with similar observations of other authors who reported that Zone 1-type of failures occurred only during CD [3,10-11].

In flowing seawater (tank and sea-raft exposures), the marked difference in measured electrochemical potentials ( $c a$. $300 \mathrm{mV}$ vs. $\mathrm{Ag} / \mathrm{AgCl}$ ) between samples tested using connected and isolated test configurations was thought to be responsible for the increased rate of $\mathrm{CD}$ failures (> $50 \%$ ). Since the carbon steel beam corroded preferentially to the stainless steel in connected test samples, the former altered the electrochemical potential of the latter and corroded preferentially in seawater. The electrons generated by the anodic reaction were available for the cathodic oxygen reduction reaction (Eq. 4) which occurred on the stainless steel sample surface underneath the polymer, generating $\mathrm{OH}^{-}$and thus leading to enhanced $\mathrm{CD}$ failures.

Although failure rates increased ( $c a .200 \%$ ), the test configuration (connected or isolated) did not have a significant effect on tests carried out using the salt-spray cabinet. This was probably due to higher temperatures and the nature of the electrolyte (salt fog mist) used in salt-spray cabinet compared to the $100 \%$ liquid electrolyte in seawater trials. The former could have limited ionic transfer and hence electrical conductivity in the system.

Although different primers, metal substrates and test configurations/environments were used, the results obtained strongly suggested that the electrochemical potentials introduced in the form of galvanic coupling of dissimilar metals (connected test) had the most dominant effect on the rate of CD failures. The failure rate due to CD was observed to decrease in the order: electrochemical potential > polymeric system > metal substrate type. A combined 
effect of any two or more of these factors could further enhance failure rates and reduce life expectancy of finished products. The lower rates of failure recorded in isolated test samples support the premise that if cable connector assemblies are electrically isolated from other metal structures and/or appurtenances, their useful service life could be increased by $>100 \%$. Such electrical isolation can be achieved by the use of suitable, non-conducting isolation sleeves or seal gaskets between the cathodically protected metallic structures and metallic receptacles (female) of the cable connector assemblies. This was demonstrated using modelled test samples in the exposure trials conducted in this research work. Isolation sleeves electrically isolated the whole sample from the carbon steel frame while still remaining connected to it. In the same manner, it is believed that isolation sleeves will isolate the whole cable connector assembly from the metal structure while still remaining connected to its female receptacle connector part. This will therefore remove the conducting pathway necessary for the oxygen reduction reaction and reduce CD (Fig. 8).

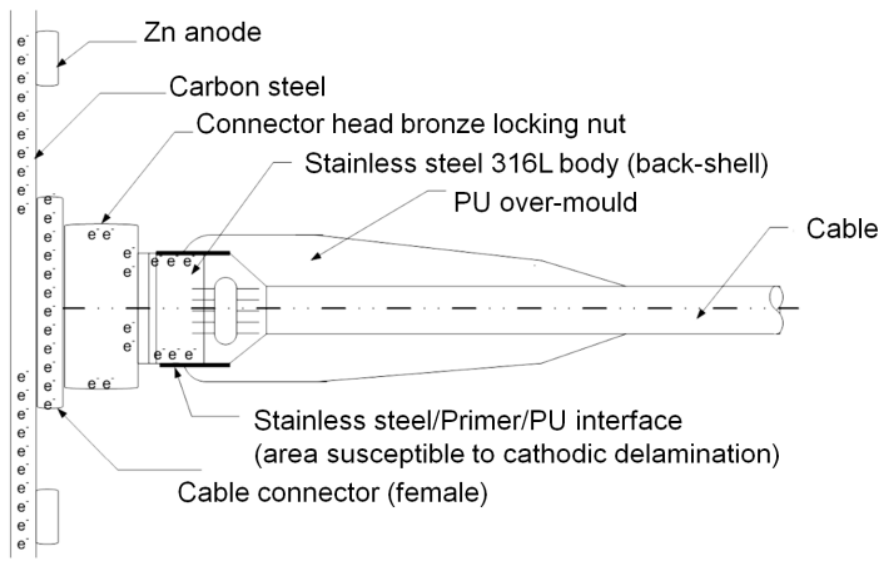

(a)

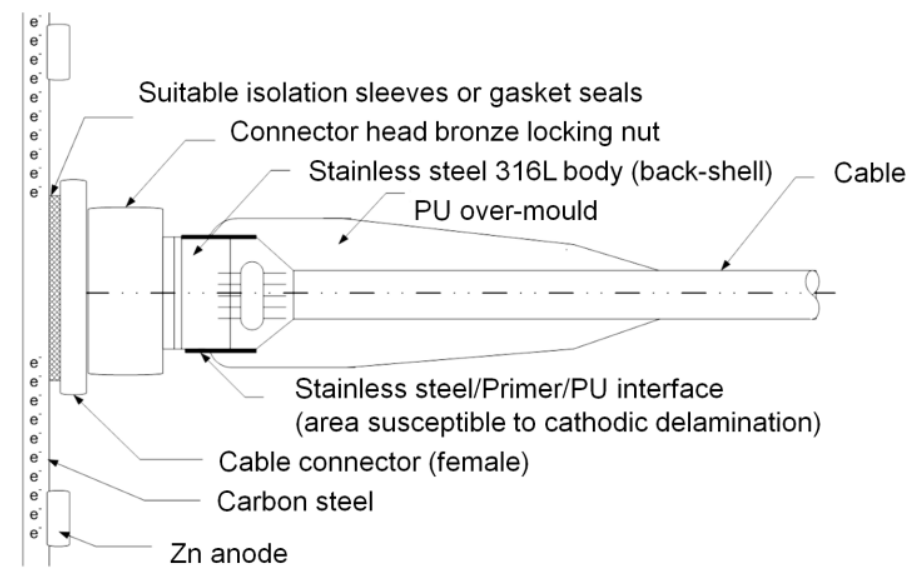

(b)

Fig. 8. Schematics of the (a) mechanism of failure due to galvanic coupling effect of a cable connector coupled to cathodically protected $(\mathrm{Zn})$ carbon steel showing the accumulation of electrons on the stainless steel 316L body (back-shell); (b) effect of using suitable isolation sleeves or seals between the cable connector female and cathodically protected metal hulls and/or appurtenances showing no accumulation of electrons on the stainless steel 316 L metal connector back-shell. 
All connected test samples were also observed to have grey encrusted deposits on the undersides of the metal plates (Fig. 9a). XRD showed these to be $\mathrm{CaCO}_{3}$ and is typical of cathodically polarised surfaces, where dissolved $\mathrm{CO}_{2}$ and $\mathrm{Mg}(\mathrm{OH})_{2}$ at high local $\mathrm{pH}$ cause precipitation of $\mathrm{CaCO}_{3}[35,36]$. The surface of the carbon steel beam, to which the test samples were attached, was covered with a layer of brown deposit, identified by XRD as goethite ( $\alpha$ $\mathrm{FeO}(\mathrm{OH}))$ and lepidocrocite $(\gamma \mathrm{FeO}(\mathrm{OH})$ ), both being corrosion products of iron (Fig. 9b) [37-39]. This was expected since the carbon steel was anodic to the stainless steel, bronze and Ti6Al4V samples.

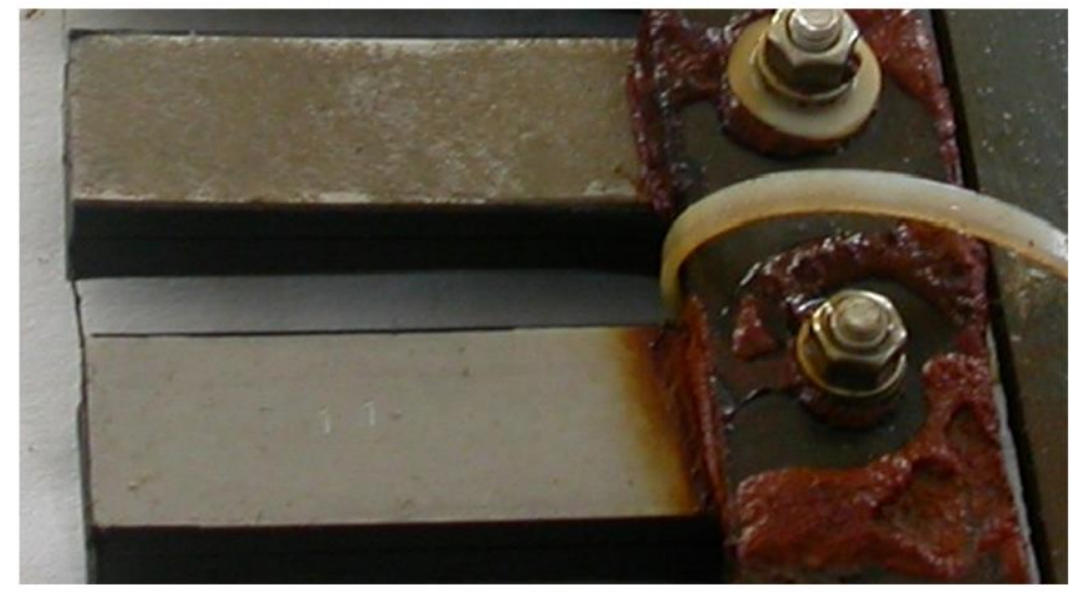

(a)

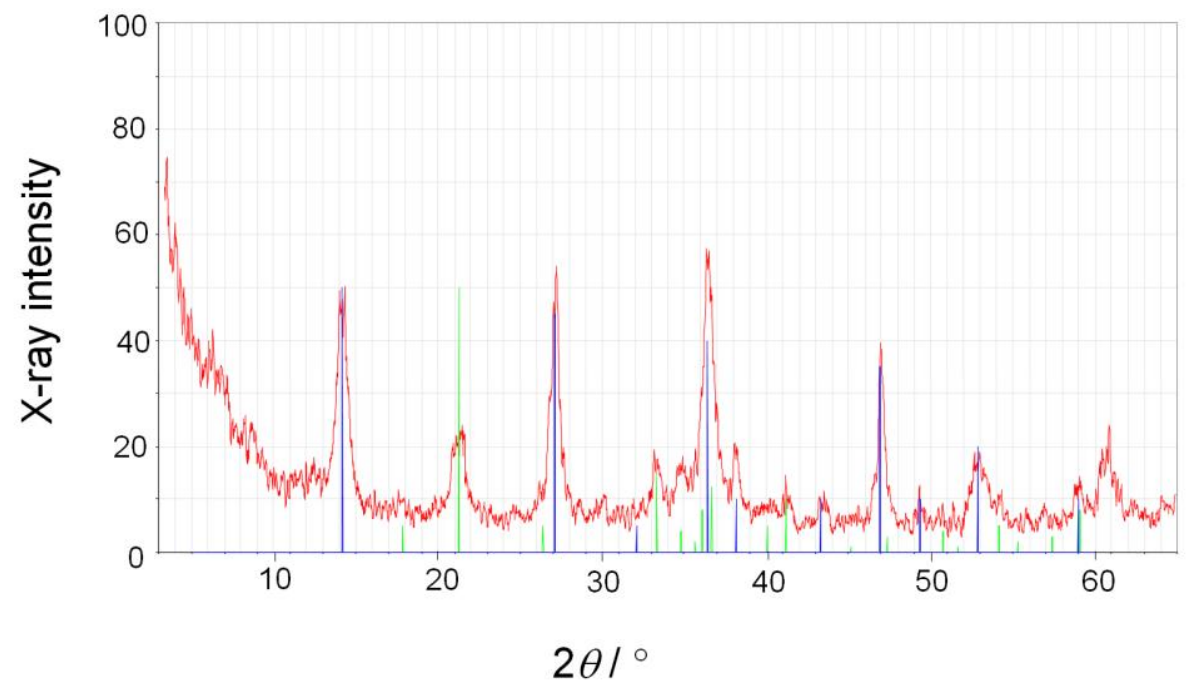

(b)

Fig. 9. (a) Photograph showing grey encrustment of $\mathrm{CaCO}_{3}$ on the underside of connected test samples (red arrow) and the absence of this deposited on the underside of isolated test samples (black arrow); (b) XRD patterns of the brown deposit found on the carbon steel beam showing diffraction patterns of two forms of iron hydroxide: goethite $(\alpha \mathrm{FeO}(\mathrm{OH})$ (green line) and lepidocrocite $(\gamma \mathrm{FeO}(\mathrm{OH})$ (blue line).

The general failure patterns of test samples were identical in all test regimes and no grey encrustment $\left(\mathrm{CaCO}_{3}\right)$ or precipitate was found on the underside of any isolated test samples nor those tested in the salt-spray cabinet (connected and isolated). This was thought to be due to the electrochemical potentials in these samples not being 
negative enough to cause the production of $\mathrm{OH}^{-}$at the interface and hence the precipitation of $\mathrm{CaCO}_{3}$ on the surface. The presence of a fog mist electrolyte in the salt-spray test could also be a contributory factor.

\section{Conclusions}

When stainless steel 316L, bronze CW451K and titanium Ti6Al4V are pretreated, coated with a primer and overmoulded with a PU encapsulant, these composites experience failure by CD when exposed in seawater and in a saltspray cabinet. The mechanism(s) and rates of failure varied with the testing conditions/configurations employed, primer and metal substrate used.

Based on the exposure trials carried out, it was clear that the metal/polymer interface of all galvanically coupled samples tested in flowing seawater were under the influence of an electrochemical potential having formed a galvanic cell in the test environment. These induced potentials were observed to have the propensity of enhancing $\mathrm{CD}$ failure in the samples. Conversely, this effect was absent in uncoupled samples observed to be under their natural or open circuit electrochemical potential in seawater.

In the same way, it can be surmised that the back-shells of cable connector assemblies, when coupled to carbon steel hulls or other metal appurtenances in seawater will be subject to the influence of electrochemical potential, i.e., -860 $\mathrm{mV}$ vs. $\mathrm{Ag} / \mathrm{AgCl}$, similar to those experienced by samples tested under galvanically coupled conditions. These potentials will be more negative when the steel structure is cathodically protected with anodes ( $\mathrm{Zn}$ or $\mathrm{Mg}$ ) or when the cable connector is connected to metal appurtenances that are less noble than the metal connector back-shell material. Under these conditions, the surface of the metal connector back-shell will be cathodically polarised due to an accumulation of free electrons. These are then available to be used in one or more of the cathodic oxygen reduction reactions in which $\mathrm{OH}^{-}$ions are produced, leading to $\mathrm{CD}$ failure. The availability of electrons on the metal surface (underneath the polymer) or at the metal connector back-shell could be the precursor to accelerated CD failures via the oxygen reduction route in cable connector assemblies. Since uncoupled samples showed better resistance to $\mathrm{CD}$ failure in seawater, this gives confidence to conclude that when a cable connector assembly is electrically isolated from the metal structure and/or appurtenances, its useful service life could be increased by $>100$ $\%$. Electrical isolation could be achieved by the use of suitable non-conducting isolation sleeves or seals between the cable connector female receptacles and the structure to which it is attached.

Short-term accelerated salt-spray tests were validated by out-door exposure testing and from the test data obtained, it can also be concluded that the choice of superior primers can significantly enhance polymer-to-metal adhesion and hence the resistance to CD. Polymer-to-metal bond life-time expectancy of PR91 was twice that of PR24 primer. In terms of metals used under conditions of open circuit electrochemical potentials in seawater, the resistance to CD was observed to increase in the order: stainless steel $316 \mathrm{~L}>$ bronze CW451K > Ti6Al4V. The failure rate due to CD was generally observed to decrease in the order: electrochemical potential > polymer system > metal substrate.

\section{Acknowledgements}

This work was funded through a Knowledge Transfer Partnership (KTP) programme between Teledyne ImpulsePDM Ltd. and University of Portsmouth, funded by the Technology Strategy Board, UK (Department for Business, Innovation and Skills, BIS). We dedicate this paper to the memory of Dr Sheelagh A. Campbell, University of Portsmouth, who sadly passed away towards the end of the project.

\section{References}

[1] Romotowski T. Accelerated life testing of marine cables and connectors. Problems, pitfalls and suggestions for improvement. Transducers Materials Branch NUWC Division Newport (Code 21320), 1176 Howell 1 Street, Newton, RI 02841, USA (2002), pp. 512-516.

[2] Corrosion Costs and Preventive Strategies in the United States, Report FHWA-RD-01-156, 2002. NACE International, 1440 South Creek Drive Houston, TX 77084-4906. http://nace.org/Publications/Cost-of-Corrosion Study/\#sthash.wA8oCwbo.dpuf

[3] Ramotowski TS, Tucker WC, Rice MA. Cathodic debonding of undersea electronic cable connectors: delamination kinetics when primers and encapsulants are bonded directly to bare metal connector backshells, Naval Undersea Warfare Center Division, Newport, Naval Sea Systems Command US Navy Newport, RI, 02841. Oceans San Diego, IEEE Xplore (2013), pp. 1-6.

[4] Arnett SL, Bray AV, Bulluck JW, Thornton CP, Rushing RA. Non-conductive coatings for underwater connector backshells, US Patent 59423331999 (1999). 
[5] Fessler RR, Markworth AJ, Parkins RN. Cathodic protection levels under disbonded coatings, Natl. Assoc. Corr. Eng. 1983; 39: 20-25.

[6] Bray AV, Arnett SL (Eds.). Testing cathodic coatings for underwater electrical connectors and marine rubberto-metal bonds, Marine Technology Society Conference Proceedings (1993), Texas Research Institute Austin, Inc., 9063 Bee Caves Road, Austin, TX 78733-6201, USA: Long Beach.

[7] Makama Z, Doble I, Nicholson D, Webb ME, Smith JR, Campbell SA. Surface preparation of stainless steel 316L, bronze CW451K and titanium Ti6Al4V for bonding to polyurethane in marine cable connector assembles. Trans. IMF 2011; 89: 237-243.

[8] Leidheiser H, Wang W. Some substrate and environmental-influences on the cathodic delamination of organic coatings. J. Coat. Technol. 1981; 53: 77-84.

[9] Leidheiser H, Wang W, Granata RD, Vedage H, White ML. Environmental-control or coatings composition as a means for reducing cathodic delamination of organic coatings. J. Coat. Technol. 1984; 56: 55-56.

[10] Watts JF, Castle JE. The application of x-ray photoelectron spectroscopy to the study of polymer-to-metal adhesion. Part 1. J. Mater. Sci. 1983; 18: 2987-3003.

[11] Watts JF. Mechanistic aspects of the cathodic delamination of organic coatings. J. Adhesion 1989; 31: 73-85.

[12] Shreir LL, Jarman RA, Burstein GT. Corrosion Control 2, 3rd Ed., Butterworth-Heinemann Ltd., Oxford, UK (1994).

[13] Furbeth W, Stratmann M. The delamination of polymeric coatings from electrogalvanised steel-a mechanistic approach. Part 1: delamination from a defect with intact zinc layer. Corros. Sci. 2001; 43: 207-227.

[14] Leng A, Streckel H, Stratmann M. The delamination of polymeric coatings from steel. Part 1. Calibration of the Kelvin probe and basic delamination mechanism. Corros. Sci. 1999; 41: 547-578.

[15] Leng A, Streckel H, Stratmann M. The delamination of polymeric coatings from steel. Part 2: First stage of delamination, effect of type and concentration of cations on delamination, chemical analysis of the interface. Corros. Sci. 1999; 41: 579-597.

[16] Montoya R, García-Galván FR, Jiménez-Morale A, Galván JC. A cathodic delamination study of coatings with and without mechanical defects. Corros. Sci. 2014; 82: 432-436.

[17] Leidheiser Jr H, Catinno J. The effect of temperature and alkali metal cations on the cathodic delamination of polybutadiene from steel. Corrosion control through a better understanding of the metallic substrate/organic coating/interface. $6^{\text {th }}$ Annual report, 21 Centre for Surface and Coating Research, Lehigh, University Bethlehem, PA 18015, USA, (1984-1985) 21-27.

[18] Leidheiser Jr. H, Wang W, Igetoft L. The mechanism for the cathodic delamination of organic coatings from a metal surface. Prog. Org. Coatings 1983; 11: 19-40.

[19] Martin JW, Saunders SM, Floyd FL, Wineburg JP. Methodologies for predicting the service lives of coating systems. Federation of Societies for Coating Technology, 492 Norristown Road, Blue Bell, PA 19422-2350, USA, June 1996).

[20] McKnight ME. Protective coating research. A look ahead. SSPC 96 conference daily, November 1996.

[21] Martin JW. Repeatability and reproducibility of field exposure results. Building and Fire Research Laboratory National Institute of Standards and Technology Gaithersburg, MD 20899, USA. ACS Symp. Ser. 2002; 805: 2-22.

[22] Jacques LFE. Accelerated and outdoor/natural exposure testing of coatings. Progr. Polym. Sci. 2000; 25: 13371362.

[23] Deflorian F, Rossi S, Fedrizzi L, Zanella C. Comparison of organic accelerated tests and natural weathering considering meteorological data. Progr. Org. Coat. 2007; 59: 244-250.

[24] CASTI Metals Red Book. Nonferrous data (2003), $4^{\text {th }}$ Edition, CASTI Publishing Inc., Edmonton, Canada.

[25] Kruger J, Boom MC. Mechanisms of wash primer action. Ind. Eng. Chem. 1956; 48: 1354-1360.

[26] Chesonis KG, Miller CE. VOC Complaint wash primer, US Army Research Laboratory, Materials Directorate, Polymer and Mechanics Division, AMSRL-MA-E Fort Belvoir, VA 22060-5606, USA. September (1994) 1-5.

[27] Painting. New Construction and Maintenance. Manual N0. EM1110-2-3400 30 $0^{\text {th }}$ April (1995), US Army Corps of Engineers, Engineering \& Design, DC 20314-1000, USA.

[28] Birley AR, Heath RJ, Scott MJ. Plastic Materials. Properties and Applications (1988), $2^{\text {nd }}$ Edition, Chapman and Hall, New York.

[29] Brydson JA. Plastic Materials (1982), $4^{\text {th }}$ Edition, Butterworth Scientific, London.

[30] Moulding procedure (2007) PDM Neptec Ltd., Alton UK.

[31] ASTM B117-03. Standard Practice for Operating Salt (Fog) Apparatus.

[32] Nelson W. Accelerated Testing: statistical models, test plans, and data analysis, (1990) John Wiley \& Sons, USA 
[33] Kendig MW, Leidheiser H. The electrical properties of protective polymer coatings as related to corrosion of the substrate. J. Electrochem. Soc. 1976; 123: 982-989.

[34] Polyurethane EMC 80A product data sheet PDM/SL/5009 Issue 7, PDM Neptec Ltd., Alton, Hampshire, UK.

[35] Nevile A, Morizot AP. Calcareous scales formed by cathodic protection - an assessment of characteristics and kinetic. J. Crystal Growth 2002; 243: 490-502.

[36] Rousseau C, Baraud F, Leleyter L, Jeannin M, Gil O. Calcareous deposits formed under cathodic protection in the presence of natural marine sediments. A 12 month experiment. Corros. Sci. 2010; 52: 2206-2218.

[37] Misawa T, Hashimoto K, Shimodair S. The mechanism of formation of iron oxide and oxyhydroxides in aqueous solutions at room temperature. Corros. Sci. 1974; 14: 131-149.

[38] OH SJ, Cook DC, Carpio JJ. Characterization of the corrosion products formed on carbon steel in a marine environment. J. Korean Phys. Soc. 2000; 36: 106-110.

[39] Selected Powder Diffraction Data for Mineral, Data Book, $1^{\text {st }}$ Edition (1974). Joint Committee on Powder Diffraction Standard, 1601 Park Lane, Swarthmore, PA 19081, USA. 